\title{
Novel manganese(II)-based deep eutectic solvents: synthesis and physical properties analysis
}

\begin{abstract}
Type IV deep eutectic solvent (DES) involves the formation of metal-based eutectics from metal salts or metal salt hydrate in combination with various hydrogen-bond donors (HBDs) such as urea, ethylene glycol or acetamide. In current study, two distinguished approaches were used to synthesize potential DESs, given as the direct heating and the evaporating methods. Successful synthesized DESs were subjected for physical properties characterization by Fourier Transform Infrared (FTIR) Spectroscopy, thermal stability, viscosity, and conductivity analyses. Five novel manganese (II)-based DESs were successfully synthesized as reported in this study. Data obtained indicated that the $\mathrm{MnCl} 2 \cdot 4 \mathrm{H} 2 \mathrm{O} \cdot$ acetamide DES exhibits the lowest freezing point $\left(27.5{ }^{\circ} \mathrm{C}\right)$, highest thermal stability $\left(193{ }^{\circ} \mathrm{C}\right.$ point of dehydration), lowest viscosity $(\mathrm{y}=112.8 \mathrm{cP})$ and the highest conductivity $(0.12723 \mathrm{mS} / \mathrm{cm})$. The findings obtained reveal the characteristics, nature or features of synthesized DESs as potential industrial solvents.
\end{abstract}

Keyword: Ionic liquid; Deep eutectic solvents; Manganese; Solvent synthesis; Physical properties 